\title{
Fairness Perception, Trust Perception, and Relationship Quality in Agricultural Supply Chains
}

\author{
Yuling Sun $\mathbb{D}^{1}{ }^{1}$ Zeyu Zhu ${ }^{1}{ }^{1}$ and Hui Yang ${ }^{2}$ \\ ${ }^{1}$ School of Economics and Management, Nanjing Tech University, Nanjing 211816, China \\ ${ }^{2}$ School of Economics and Management, Nanjing University of Science and Technology, Nanjing 210094, China \\ Correspondence should be addressed to Yuling Sun; syl_nj@njtech.edu.cn
}

Received 2 October 2020; Revised 20 February 2021; Accepted 1 March 2021; Published 10 March 2021

Academic Editor: Yong He

Copyright (c) 2021 Yuling Sun et al. This is an open access article distributed under the Creative Commons Attribution License, which permits unrestricted use, distribution, and reproduction in any medium, provided the original work is properly cited.

Suppliers are important members of the agricultural supply chain. Moreover, their behavior decisions may affect the sustainable development of the agricultural supply chain. Considering agricultural supplier trust, this study examines the direct impact of trust perception on relationship quality and the indirect impact of supplier fairness perception on relationship quality. Based on the survey data of agricultural product suppliers, this study uses the structural equation model method for empirical analysis. The analysis results show that both fairness perception and trust perception have a significant positive impact on the relationship quality of the agricultural supply chain. Trust perception particularly has a positive direct impact on the relationship quality of the agricultural supply chain, while fairness perception has an indirect influence on the relationship quality of the agricultural supply chain through trust perception. In addition, information sharing, price satisfaction, income level, and environmental certainty have a significant positive impact on suppliers' fairness perception. Therefore, retailers comprehensively consider both fairness perception and trust perception of suppliers, which will help improve the relationship quality of the supply chain.

\section{Introduction}

Many experiments in behavioral economics have shown that the fairness perception of decision-makers refers to the comparison between the efforts and benefits of oneself and that of others, wherein the idea of fairness is derived [1]. In China, the agricultural supply chain is usually dominated by retailers or wholesalers. The suppliers only obtain less revenue and bear too many market risks [2]. The inequality of distributed wealth could prompt suppliers to take certain illegal actions to reduce production costs and increase their own profits. These behaviors may cause agricultural product quality safety incidents. For example, the Shanghai Shenglu Food Company dyes white flour into cornmeal buns and Heinz Meiweiyuan (Guangzhou) Food Company adds "Sudan Red No. 1" to chili sauce. These incidents damage the relationship quality between agricultural supply chains. Therefore, supplier fairness perception is one of the key factors affecting the stability of supply chain cooperation [3]. However, trust has a positive role in promoting relationship quality [4]. If suppliers trust retailers, they will make effort to maintain the stability of the quality of agricultural products for long-term cooperation. It is helpful to improve the efficiency of cooperation and the stability of relationship quality [5]. Once the agricultural product supplier loses trust in the retailer, conducting behaviors that damage the relationship quality of the agricultural supply chain is possible [6]. Suppliers' trust to retailers is an important part of supply chain management [7].

In supply chain management research, the relationship quality of the supply chain is important for describing the basic characteristics of the supply chain. Food safety and quality issues have largely affected the relationship quality of the supply chain [8]. Fairness perception and trust perception of suppliers may affect the relationship quality of the agricultural supply chain. As we have shown, some scholars have conducted empirical studies on the influence of fairness perception on relationship quality, and they found that fairness perception has a positive effect on relationship quality $[9,10]$. In addition, other scholars have studied the 
influence of trust perception on relationship quality [11]. However, their main concern was the impact of the retailer's fairness perception or trust perception on relationship quality. To the best of our knowledge, there has been little research on the impact of both suppliers' fairness perception and trust perception on the relationship quality of the agricultural supply chain. Based on survey data sets of agricultural product suppliers, this study analyzes the impact of agricultural product suppliers' fairness perception and trust perception on the relationship quality of the supply chain. The research results will provide scientific guidance and suggestions for the sustainable development of agricultural supply chains.

\section{Theoretical Background and Assumptions}

2.1. Factors Influencing Suppliers' Fairness Perception. Both distributive and procedural fairness are important dimensions for measuring fairness perception and have been widely used in previous literature. Many scholars have studied the influence of distributive and procedural fairness in the supply chain and their own influence $[12,13]$. This study uses both distributive and procedural fairness to describe the fairness perception of agricultural product suppliers. Informational fairness and interactional fairness are also reflected in the article. Openness and transparency of information and the equality of information exchange are considered through information sharing, and equality of both agricultural product suppliers' transaction process and interaction is considered through procedural fairness.

Price satisfaction is essential and affects fairness perception [14]. Price satisfaction has a positive and significant impact on fairness perception [15]. Simultaneously, price satisfaction can affect not only the degree of fairness perception but also the cooperation between suppliers and retailers in the supply chain of agricultural products [16]. Higher price satisfaction will make cooperation between agricultural product suppliers and retailers more stable and lasting. This study makes the following assumptions:

H1a: price satisfaction has a positive impact on distributive fairness

H1b: price satisfaction has a positive impact on procedural fairness

Studies have shown that information sharing could improve supply chain performance [17]. Therefore, information sharing is an essential role in the cooperation process of supply chain members. For example, information sharing can promote operational performance improvement, reduce supply chain costs, and increase supply chain profits $[18,19]$. Simultaneously, information sharing has a positive impact on fairness [20]. Information sharing and fairness perception are considered closely related, and information sharing can have a certain impact on fairness perception. As the degree of information sharing increases, agricultural product suppliers can obtain more information. This study makes the following assumptions:
$\mathrm{H} 2 \mathrm{a}$ : information sharing has a positive impact on distributive fairness

$\mathrm{H} 2 \mathrm{~b}$ : information sharing has a positive impact on procedural fairness

Income is the main indicator reflecting utility and satisfaction [21]. Income inequality triggers the unfairness perception of agricultural product suppliers, which can significantly reduce the enthusiasm of agricultural product suppliers. Changes in income levels significantly affect fairness perception [22]. When the income level fluctuates abnormally, it will even affect the fairness of the whole society and cause people to change the concept of social fairness [23]. An increase in income level will enhance the fairness perception of suppliers of agricultural products and promote cooperation between suppliers and retailers. This study makes the following assumptions:

H3a: income level has a positive impact on distributive fairness

$\mathrm{H} 3 \mathrm{~b}$ : income level has a positive impact on procedural fairness

Environmental certainty has a significant impact on fairness perception, namely, distributive fairness and procedural fairness, and has an impact on the stability of supply chain partnerships [24]. Therefore, the uncertainty of the agricultural product market environment brings risk and unfairness perception to agricultural product suppliers. Increasing environmental certainty promotes the fairness perception of agricultural product suppliers and stabilizes the cooperative relationship of agricultural supply chains. This study makes the following assumptions:

H4a: environmental certainty has a positive impact on distributive fairness

H4b: environmental certainty has a positive impact on procedural fairness

2.2. Fairness Perception and Trust Perception. This study divides trust perception into two dimensions: integrity trust and good faith trust. Integrity trust means that the supplier of agricultural products trusts the promise from the retailer and regards the retailer as the most loyal partner. Good faith trust shows that the supplier of agricultural products fully trusts that the retailer can provide assistance, support, and understanding.

In the agricultural supply chain, both fairness perception and trust perception play very important roles. However, no clear conclusion about the relationship between trust perception and fairness perception exists. We assume that fairness perception affects trust perception among members of the agricultural supply chain.

On the one hand, distributive fairness has a significant impact on trust perception. Distributive fairness is mainly manifested in the fairness of income distribution. When the income or benefits' distribution was unfair, people's participation also became affected, thereby affecting trust 
[25, 26]. Christopher and Matthew [27] proved that trust was affected by a social distribution or unfair income distribution, and unfair income distribution reduced public trust. Sonja and Juan [28] highlighted that unfair income distribution had a negative impact on trust. Distributive fairness can be the decisive factor of trust perception. In the agricultural supply chain, unfair income distribution will stimulate conflicts between suppliers and retailers, affect the trust of both parties, and damage the willingness of both parties to continue cooperating. Therefore, distributive fairness has a certain impact on trust perception.

On the other hand, procedural fairness could affect trust perception. Procedural fairness is defined as the fairness of participants during the planning process [29]. Trust is usually formed during the planning process [30, 31]. Christoph [32] showed that procedural fairness directly affected participants' trust. Gross [33] proved that procedural fairness has a positive impact on trust. Procedural fairness is an important determinant of trust perception in the agricultural supply chain because procedural fairness reduces conflicts of interest, enhances the stability of the supply chain, and increases trust between both parties. Good mutual trust helps reduce the adverse effects of communication, stabilize the supply chain environment, and increase market vitality. Thus, procedural fairness affects trust perception to a certain extent.

Aryee et al. [34] proved that both distributive fairness and procedural fairness affected trust. In addition, distributive and procedural fairness has a comprehensive impact on trust fairness. Ghasem et al. [35] further highlighted that distributive fairness has a more significant impact on trust. Therefore, trust fairness in agricultural product suppliers will be affected by fairness perception. This study makes the following assumptions:

H5a: distributive fairness has a positive impact on integrity trust

H5b: distributive fairness has a positive impact on good faith trust

H6a: procedural fairness has a positive impact on integrity trust

H6b: procedural fairness has a positive impact on good faith trust

2.3. Trust Perception and Relationship Quality. Commitment is essential in relationship quality, and supplier trust will have a significant impact on commitment [36]. From a psychological point of view, commitment is largely affected by trust, and this effect is enduring [37]. Some scholars have found that fairness has an indirect impact on commitment, and trust has a direct impact on commitment $[38,39]$. Suppliers will maintain stable commitment and long-term cooperation with the retailer if they trust the retailer. This study makes the following assumptions:

H7a: integrity trust has a positive impact on commitment
H7b: good faith trust has a positive impact on commitment

Trust perception is critical to investment willingness. Trust will affect investment willingness and income [40,41]. The willingness of suppliers to continue investing is also affected by trust [42]. Therefore, the trust perception of agricultural product suppliers has an impact on investment willingness. This study makes the following assumptions:

H8a: integrity trust has a positive impact on investment willingness

H8b: good faith trust has a positive impact on investment willingness

Continuity expectation means that the agricultural product suppliers do not want to change the relationship in a short time but to keep cooperating with the retailer. Trust will affect the continuity of the cooperative relationship and has an intangible effect on future cooperation between two parties [43]. Trust is related to fairness, which affects the results of cooperation and the possibility of long-term cooperation, that is, continuous expectations $[44,45]$. Thus, the continuity expectation is possibly affected by trust perception. This study makes the following assumptions:

H9a: integrity trust has a positive impact on continuity expectations

H9b: good faith trust has a positive impact on continuity expectations

Based on the above analysis, this study establishes a theoretical model and research hypothesis framework of the relationship between fairness perception, trust perception, and agricultural supply chain quality, as shown in Figure 1.

\section{Methods of Empirical Research}

3.1. Variable Definitions and Measurements. This study examines the impact of both fairness perception and trust perception on relationship quality. The factors influencing fairness perception include price satisfaction, information sharing, income level, and environmental certainty. Fairness perception is separated into distributive and procedural fairness. Trust perception includes integrity trust and good faith trust. Relationship quality comprises commitment, investment willingness, and continuity expectations. To ensure the reliability and validity of the scale, this study adopts a seven-point Likert scale widely used in empirical research.

This article defines price satisfaction as the degree of satisfaction of suppliers with agricultural product prices, with five items, the scale of which comes from Hellberg and Spiller [46]. This article defines information sharing as the ability of agricultural product suppliers to share their own information with retailers with six items, and its scale is adapted from Frazier et al. [47]. Income level is defined as the profit that the retailer can bring to the agricultural product supplier. The scale is rooted in the study by Anderson and Narus [48], with four items. Environmental uncertainty means that the demand and sales forecasting of 


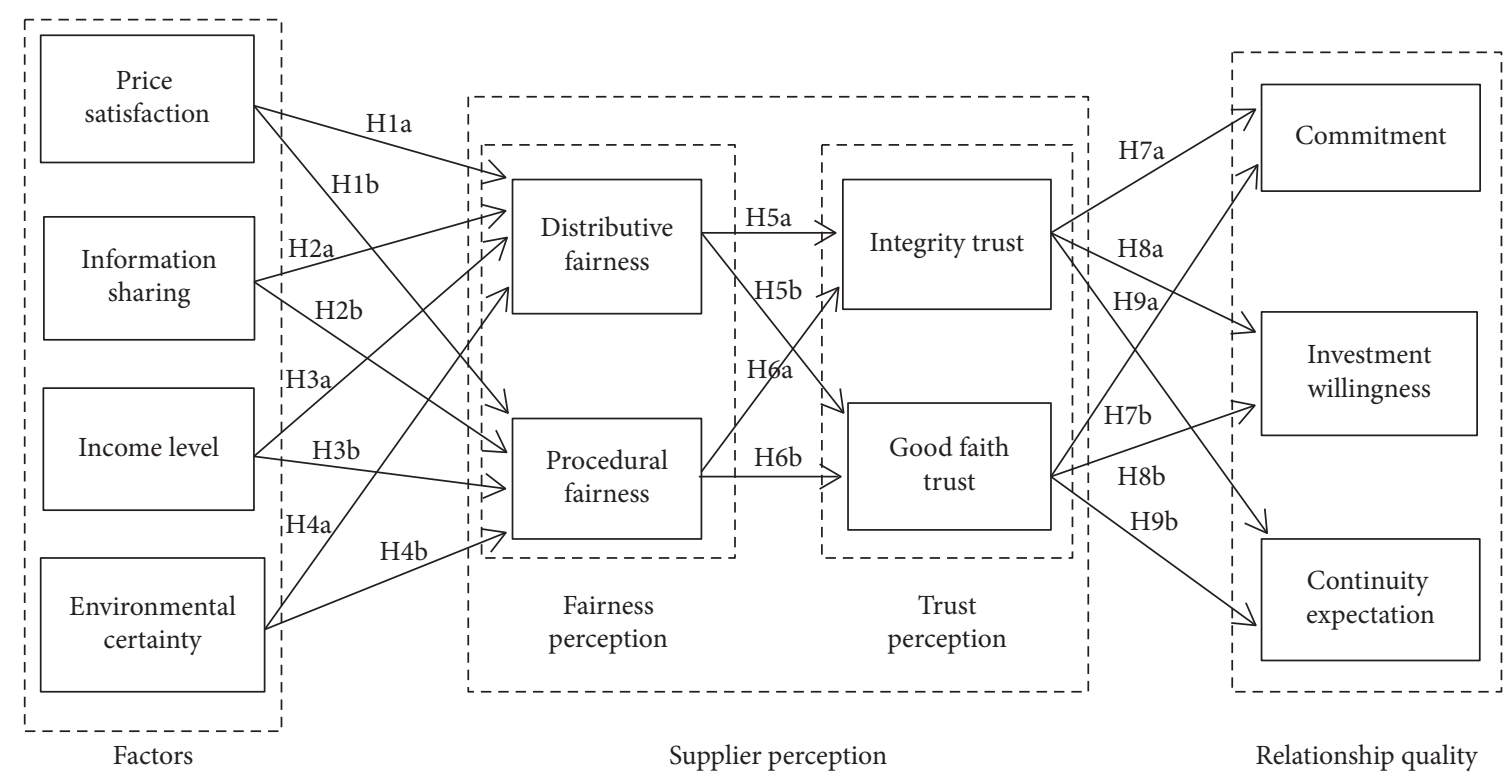

FIgure 1: Theoretical model.

suppliers on the agricultural product market is not ascertainable, and its scale is adapted from Heide and John [49].

This study defines distributive fairness as the distribution of profit being fair in the cooperation between agricultural product suppliers and retailers and that procedural fairness as the process of cooperation between suppliers and retailers remaining fair. The scale of distributive fairness is measured by five items, and the scale is derived from Price and Mueller [50]. The scale of procedural fairness is adapted from Kim and Mauborgne [51], with eight items. Integrity trust means that agricultural product suppliers trust the retailer's promises and suggestions, and good faith trust means that agricultural product suppliers trust the retailer's support and assistance. Integrity trust and good faith trust are measured by five items, and the scale comes from Kumar et al. [52].

Commitment means that the supplier of agricultural products is willing to make corresponding promises to the retailers with three items, and the scale comes from Meyer et al. [53]. Investment willingness is defined as the willingness of agricultural product suppliers to invest and cooperate with retailers. The scale is selected from Kumar et al. [52], which is described by three items. This article defines continuity expectation as the idea of long-term cooperation between agricultural product suppliers and retailers with three items, and the source of the scale is the study by Frazier et al. [47].

3.2. Sample Selection and Data Collection. This article conducts surveys via questionnaire. The objects of the questionnaire are representative suppliers from wholesale markets of agricultural products in various cities, and most of them have rich experience in the agricultural industry. The objects of the questionnaire cover major cities in Jiangsu Province. The questionnaire is distributed to agricultural product suppliers through e-mail and visits. A total of 1,000 questionnaires were distributed, and 562 were returned. The questionnaires were screened after the questionnaires were returned, and 112 questionnaires were eliminated, because the subjects of 53 questionnaires did not meet the requirements of middle- and high-level supplier managers, and the result of 13 questionnaires had the same blockbuster options. In addition, 25 questionnaires contained missing information, and 21 questionnaires showed wrong answers to reverse questions and polygraph questions. Finally, 450 valid questionnaires were obtained with an effective recovery rate of $45 \%$.

\section{Empirical Research Results}

4.1. Reliability and Validity Analysis. This study used SPSS 25.0 to test the reliability and validity of the questionnaire based on the collected data. Both reliability and validity were analyzed. The specific analysis results are shown in Table 1.

The study analyzes the Cronbach's $\alpha$ coefficient from 11 aspects such as price satisfaction, information sharing, income level, environmental certainty, distributive fairness, procedural fairness, integrity trust, good faith trust, commitment, investment willingness, and continuity expectation. According to the reliability analysis, the Cronbach's $\alpha$ value of the total variable was 0.952 , indicating that the reliability of the total sample data was good. From Table 1, that Cronbach's $\alpha$ values in various aspects are $0.732-0.849$, which is all greater than 0.7 acceptable values. This shows that each indicator has high internal consistency, and each variable has good reliability.

The study also calculates KMO (Kaiser-Meyer-Olkin) values of the total sample and the chi-square value of Bartlett's sphericity test and analyzes the factor load of each variable. According to the validity analysis, the KMO value is 0.912, and Bartlett's sphericity chi-square value is 15706.585 . This means that the sample data are very suitable for analysis. Simultaneously, the factor load of each variable is greater than 0.5 , which indicates that the sample data have good validity. 
TABLE 1: Reliability and validity analysis of variables.

\begin{tabular}{|c|c|c|c|}
\hline Variable & Question & $\alpha$ & Factor load \\
\hline \multirow{5}{*}{ Price satisfaction } & Q1-1 & \multirow{5}{*}{0.732} & 0.792 \\
\hline & Q1-2 & & 0.764 \\
\hline & Q1-3 & & 0.683 \\
\hline & Q1-4 & & 0.776 \\
\hline & Q1-5 & & 0.815 \\
\hline \multirow{6}{*}{ Information sharing } & Q2-1 & \multirow{6}{*}{0.787} & 0.591 \\
\hline & Q2-2 & & 0.745 \\
\hline & Q2-3 & & 0.798 \\
\hline & Q2-4 & & 0.634 \\
\hline & Q2-5 & & 0.739 \\
\hline & Q2-6 & & 0.719 \\
\hline \multirow{4}{*}{ Income level } & Q3-1 & \multirow{4}{*}{0.849} & 0.846 \\
\hline & Q3-2 & & 0.684 \\
\hline & Q3-3 & & 0.735 \\
\hline & Q3-4 & & 0.572 \\
\hline \multirow{4}{*}{ Environmental certainty } & Q4-1 & \multirow{4}{*}{0.815} & 0.742 \\
\hline & Q4-2 & & 0.847 \\
\hline & Q4-3 & & 0.692 \\
\hline & Q4-4 & & 0.788 \\
\hline \multirow{5}{*}{ Distributive fairness } & Q5-1 & \multirow{5}{*}{0.774} & 0.792 \\
\hline & Q5-2 & & 0.745 \\
\hline & Q5-3 & & 0.761 \\
\hline & Q5-4 & & 0.831 \\
\hline & Q5-5 & & 0.579 \\
\hline \multirow{8}{*}{ Procedural fairness } & Q5-6 & \multirow{8}{*}{0.831} & 0.543 \\
\hline & Q5-7 & & 0.861 \\
\hline & Q5-8 & & 0.789 \\
\hline & Q5-9 & & 0.767 \\
\hline & Q5-10 & & 0.668 \\
\hline & Q5-11 & & 0.812 \\
\hline & Q5-12 & & 0.792 \\
\hline & Q5-13 & & 0.755 \\
\hline \multirow{5}{*}{ Integrity trust } & Q6-1 & \multirow{5}{*}{0.792} & 0.696 \\
\hline & Q6-2 & & 0.867 \\
\hline & Q6-3 & & 0.571 \\
\hline & Q6-4 & & 0.724 \\
\hline & Q6-5 & & 0.761 \\
\hline \multirow{5}{*}{ Good faith trust } & Q6-6 & \multirow{5}{*}{0.763} & 0.740 \\
\hline & Q6-7 & & 0.716 \\
\hline & Q6-8 & & 0.763 \\
\hline & Q6-9 & & 0.738 \\
\hline & Q6-10 & & 0.762 \\
\hline \multirow{3}{*}{ Commitment } & Q7-1 & \multirow{3}{*}{0.826} & 0.849 \\
\hline & Q7-2 & & 0.654 \\
\hline & Q7-3 & & 0.737 \\
\hline \multirow{3}{*}{ Investment willingness } & Q8-1 & \multirow{3}{*}{0.779} & 0.799 \\
\hline & Q8-2 & & 0.782 \\
\hline & Q8-3 & & 0.813 \\
\hline \multirow{3}{*}{ Continuity expectation } & Q9-1 & & 0.726 \\
\hline & Q9-2 & 0.786 & 0.751 \\
\hline & Q9-3 & & 0.798 \\
\hline
\end{tabular}

4.2. Model Fitness Analysis. This study uses AMOS25.0 software to perform confirmatory factor analysis (CFA) for each variable. These variables include price satisfaction, information sharing, income levels, environmental certainty, distributive fairness, procedural fairness, integrity trust, good faith, trust, commitment, investment willingness, and continuity expectation. The model's goodness-of-fit is shown in Table 2. According to the standard of goodness-of-fit [54], $\chi^{2} / \mathrm{d} f<2$, RMSEA $<0.05$, GFI, AGFI, NFI, CFI, TLI, RFI, and IFI are all equal to or greater than 0.90 , thereby confirming a favorable goodness-of-fit. These data indicate that the model has a great goodness-of-fit. The research results of the sample data in this study show that the absolute fit index $\chi^{2} / \mathrm{d} f=1.431, \quad \mathrm{RMSEA}=0.039$, the relative fit index $\mathrm{GFI}=0.912, \quad \mathrm{AGFI}=0.964, \quad \mathrm{NFI}=0.937, \quad \mathrm{CFI}=0.957$, $\mathrm{TLI}=0.953$, RFI $=0.926$, and IFI $=0.971$. The goodness-of-fit of the model can be considered well (see Table 2).

The average variance extraction (AVE) of each variable is $0.551-0.741$, and the combined reliability (CR) of each variable is $0.739-0.956$. Thus, all average variance extractions (AVEs) are greater than 0.5 , and all combined reliabilities (CRs) are greater than 0.7. In short, all relative fitting indexes satisfy the fitting standard. Model adaptability is considered good in this study (see Table 3).

4.3. Path Analysis. The study conducts a path analysis using AMOS 25.0 to analyze the influencing factors of fairness perception of agricultural product suppliers, fairness perception, trust perception, and relationship quality. The analysis results are shown in Figure 2.

From Figure 2, all $p<0.001$ are established; that is, all paths have reached a highly significant level. This study further analyzes the correlation of variables, path coefficients, and the significant levels they reach, as shown in Table 4 . The correlation $p$ reflects the degree of correlation. When $p<0.05$, the correlation is significant; when $p<0.01$, the correlation is more significant; when $p<0.001$, the correlation is highly significant. From Table 4, hypotheses H1a, H1b, H2a, H2b, H3a, H4a, H4b, H5a, H6a, H6b, H7b, $\mathrm{H} 8 \mathrm{~b}$, and $\mathrm{H} 9 \mathrm{~b}$ have proven to be highly significant correlations.

4.4. Results Analysis. This article analyzes the reliability and validity of the sample data. The analysis results show that the data are all valid and reliable. The structural equation modeling (SEM) method is used to test the hypothesis, and the influence between all paths is tested.

The results showed that all assumptions about fairness perception and trust perception have been verified. Concerning influencing factors of fairness perception, both price satisfaction and information sharing and environmental certainty have a highly significant positive impact on the fairness perception of suppliers. So, the supplies will feel higher fairness if a more reasonable wholesale price is given by the retailers. The increased information-sharing degree of retailers will promote an increase of suppliers' fairness perception and then the increased fairness perception of suppliers is conducive to mutual trust between suppliers and retailers. Furthermore, when the demand market is more predictable and the scale of market demand is more stable, suppliers' fairness perception will increase. In addition, information sharing has strong positive impacts on suppliers' procedural fairness. Both price satisfaction and income level have a more significant impact on distributive 
TABLE 2: Goodness-of-fit of the model.

\begin{tabular}{lccccccccc}
\hline Statistical test & $\chi^{2} / \mathrm{d} f$ & RMSEA & GFI & AGFI & NFI & CFI & TLI & RFI & IFI \\
\hline Adaptation standard & $<2$ & $<0.05$ & $>0.90$ & $>0.90$ & $>0.90$ & $>0.90$ & $>0.90$ & $>0.90$ & $>0.90$ \\
Fitted value & 1.431 & 0.039 & 0.912 & 0.964 & 0.937 & 0.957 & 0.953 & 0.926 & 0.971 \\
\hline
\end{tabular}

TABle 3: Model adaptability.

\begin{tabular}{|c|c|c|c|c|}
\hline Variable & $\mathrm{M}$ & $\mathrm{SD}$ & AVE & $\mathrm{CR}$ \\
\hline (1) Price satisfaction & 4.757 & 1.135 & 0.589 & 0.877 \\
\hline (2) Information sharing & 4.657 & 1.147 & 0.501 & 0.856 \\
\hline (3) Income level & 4.692 & 1.171 & 0.513 & 0.805 \\
\hline (4) Environmental certainty & 4.674 & 1.126 & 0.592 & 0.852 \\
\hline (5) Distributive fairness & 4.781 & 1.119 & 0.557 & 0.861 \\
\hline (6) Procedural fairness & 4.734 & 1.152 & 0.569 & 0.912 \\
\hline (7) Integrity trust & 4.520 & 1.114 & 0.533 & 0.849 \\
\hline (8) Good faith trust & 4.725 & 1.065 & 0.554 & 0.861 \\
\hline (9) Commitment & 4.919 & 1.132 & 0.564 & 0.793 \\
\hline (10) Investment willingness & 4.608 & 1.098 & 0.637 & 0.840 \\
\hline (11) Continuity expectation & 4.510 & 1.157 & 0.576 & 0.803 \\
\hline
\end{tabular}

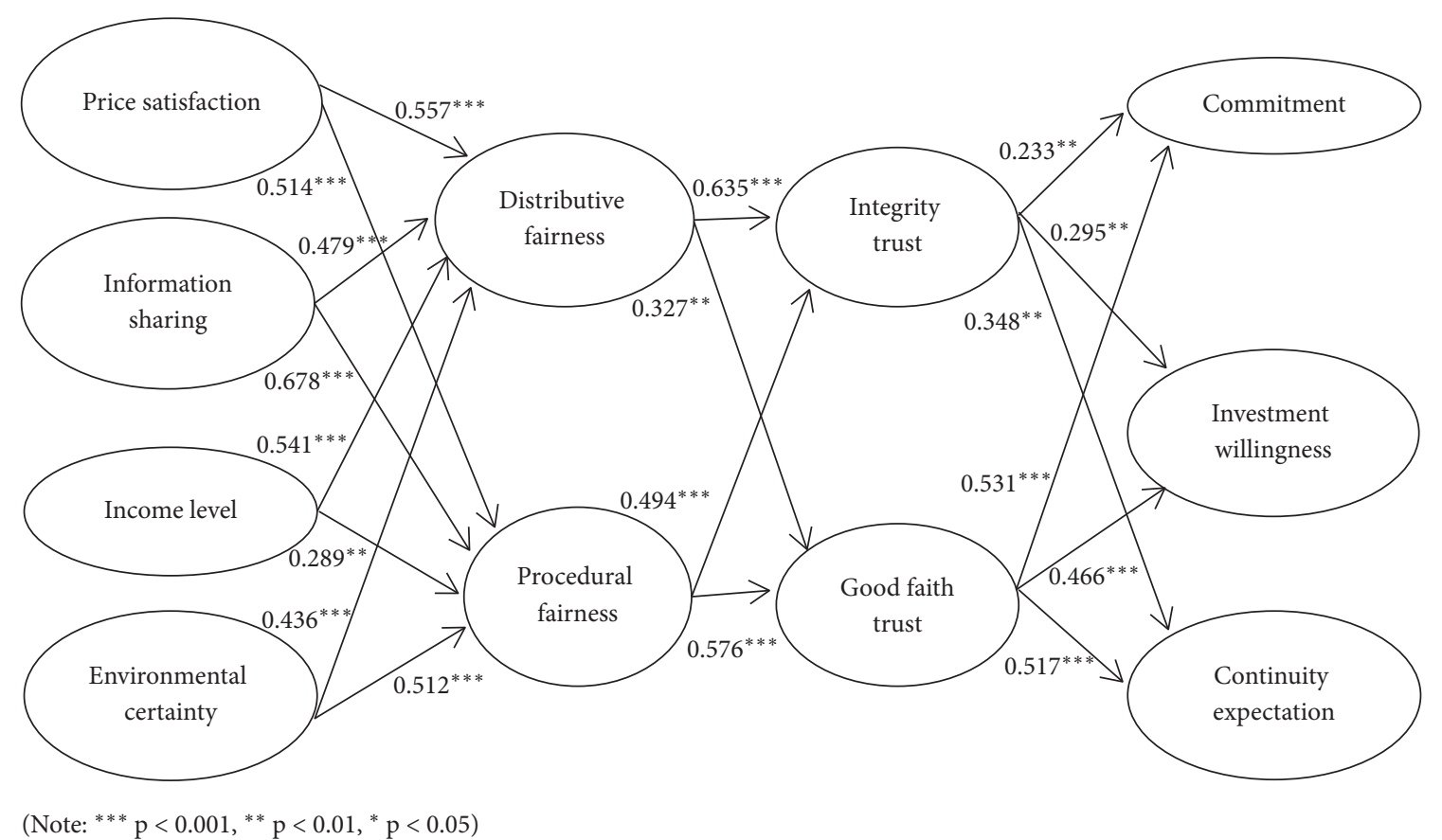

FIgURE 2: Model path analysis diagram.

fairness than on procedural fairness. But environmental certainty has a greater impact on procedural fairness than distributive fairness.

Through the impact of fairness perception on trust perception, it is found that procedural fairness and distributive fairness have a highly significant positive impact on both integrity trust and good faith trust. Improving suppliers' fairness perception will increase the suppliers' trust in retailers and enhance the long-term cooperation between the two sides. The impact of distributive fairness on integrity trust is more significant than on good faith trust. Procedural fairness has a highly significant positive impact on integrity trust and a more significant positive impact on good faith trust.

Considering the influence of trust perception on relationship quality, integrity trust and good faith trust both have a significant positive impact on relationship quality. On the one hand, a higher supplier's trust perception will induce a greater possibility of cooperation with the retailer. This will be conducive to continuous and long-term cooperation between suppliers and retailers. On the other hand, the increased trust of suppliers in retailers will prompt suppliers to make more reliable commitments to retailers, such as long-term cooperation and quality assurance, which is 
TABLE 4: Hypothesis verification results.

\begin{tabular}{|c|c|c|c|c|}
\hline Suppose & Path & Path coefficient & $p$ & Conclusion \\
\hline H1a & Price satisfaction $\longrightarrow$ distributive fairness & 0.557 & $* * *$ & Stand by \\
\hline $\mathrm{H} 1 \mathrm{~b}$ & Price satisfaction $\longrightarrow$ procedural fairness & 0.514 & $* * *$ & Stand by \\
\hline $\mathrm{H} 2 \mathrm{a}$ & Information sharing $\longrightarrow$ distributive fairness & 0.479 & $* * *$ & Stand by \\
\hline $\mathrm{H} 2 \mathrm{~b}$ & Information sharing $\longrightarrow$ procedural fairness & 0.678 & $* * *$ & Stand by \\
\hline $\mathrm{H} 3 \mathrm{a}$ & Income level $\longrightarrow$ distributive fairness & 0.541 & $* * *$ & Stand by \\
\hline $\mathrm{H} 3 \mathrm{~b}$ & Income level $\longrightarrow$ procedural fairness & 0.289 & $* *$ & Stand by \\
\hline $\mathrm{H} 4 \mathrm{a}$ & Environmental certainty $\longrightarrow$ distributive fairness & 0.436 & $* * *$ & Stand by \\
\hline $\mathrm{H} 4 \mathrm{~b}$ & Environmental certainty $\longrightarrow$ procedural fairness & 0.512 & $* * *$ & Stand by \\
\hline $\mathrm{H} 5 \mathrm{a}$ & Distributive fairness $\longrightarrow$ integrity trust & 0.635 & $* * *$ & Stand by \\
\hline $\mathrm{H} 5 \mathrm{~b}$ & Distributive fairness $\longrightarrow$ good faith trust & 0.327 & $* *$ & Stand by \\
\hline H6a & Procedural fairness $\longrightarrow$ integrity trust & 0.494 & $* * *$ & Stand by \\
\hline $\mathrm{H} 6 \mathrm{~b}$ & Procedural fairness $\longrightarrow$ good faith trust & 0.576 & $* * *$ & Stand by \\
\hline $\mathrm{H} 7 \mathrm{a}$ & Integrity trust $\longrightarrow$ commitment & 0.233 & $* *$ & Stand by \\
\hline $\mathrm{H} 7 \mathrm{~b}$ & Good faith trust $\longrightarrow$ commitment & 0.531 & $* * *$ & Stand by \\
\hline $\mathrm{H} 8 \mathrm{a}$ & Integrity trust $\longrightarrow$ investment willingness & 0.295 & $* *$ & Stand by \\
\hline $\mathrm{H} 8 \mathrm{~b}$ & Good faith trust $\longrightarrow$ investment willingness & 0.466 & $* * *$ & Stand by \\
\hline H9a & Integrity trust $\longrightarrow$ continuity expectation & 0.348 & ** & Stand by \\
\hline $\mathrm{H} 9 \mathrm{~b}$ & Good faith trust $\longrightarrow$ continuity expectation & 0.517 & $* * *$ & Stand by \\
\hline
\end{tabular}

conducive to the stable development of the supply chain. Compared with integrity trust, good faith trust has a more significant impact on relationship quality. The results of the study show that integrity trust has the most significant impact on continuity expectations. Good faith trust has strong positive impacts on commitment.

Our study shows that the influencing factors of fairness perception have a significant positive impact on supplier perception. Simultaneously, supplier perception has a significant positive impact on relationship quality.

Using Bollen's analysis method [55], this study further analyzes the indirect impact of fairness perception on the relationship quality of the supply chain. The analysis results show that the indirect effects of distributive fairness and procedural fairness on commitments are 0.43 and 0.39 , the indirect effects on investment willingness are 0.45 and 0.40 , and the indirect effects on continuity expectations are 0.47 and 0.44 , respectively. Therefore, fairness perception has a positive indirect impact on the relationship quality of the agricultural supply chain. Among them, distributive fairness has the most significant indirect influence on commitment, investment willingness, and continuity expectations. Distributive fairness is the key to improve the relationship quality of the supply chain.

\section{Main Conclusions and Research Prospects}

5.1. Main Conclusion. Based on the perspective of agricultural product suppliers, this study uses the structural equation model to analyze the impact of agricultural product suppliers' fairness perception and trust perception on the relationship quality of the agricultural supply chain. The conclusions of this study mainly include the following four aspects. (1) Price satisfaction, information sharing, and income level have a significant positive impact on fairness perception, wherein information sharing has the most significant impact on fairness perception. (2) Fairness perception has a significant positive impact on suppliers' trust perception. (3) Suppliers' trust perception has a significant positive impact on the relationship quality of the supply chain. (4) Fairness perception has a positive indirect impact on the relationship quality of the supply chain through trust perception.

Based on the above conclusions, this article presents four management suggestions. First, retailers should strengthen information sharing with suppliers, such as sharing product information, business development, and company development status. In the supply chain, information sharing has become a key factor in supply chain cooperation. Enhancing information sharing between retailers and suppliers will improve suppliers' fairness perception and promote cooperation between two parties.

Second, retailers need to reasonably set purchase prices and conduct profit distribution so that the income of agricultural product suppliers can be guaranteed and suppliers' distributive fairness perception can be improved. In addition, retailers also need to prohibit fraud in the transaction process and enhance mutual frankness to improve suppliers' procedural fairness perception. In the agricultural supply chain, whether the profits and returns obtained by suppliers are fair and whether they are treated fairly during transactions with retailers are important factors affecting suppliers' trust perception.

Third, the retailer should ensure the fairness of the supplier and enhance the sincerity of cooperation by proactively requesting the expansion of the cooperation period between the two parties and boosting willingness to cooperate, which can increase suppliers' trust perception. Because agricultural product quality risk and supply risk mainly come from suppliers, increasing suppliers' trust in retailers will improve the relationship quality of the agricultural supply chain.

Fourth, retailers should strengthen cooperation with suppliers by increasing the quantity and frequency of 
purchases of agricultural products and reduce conflicts in the transaction process by satisfying supplier demand and adopting supplier opinions. It will enhance suppliers' fairness perception and trust perception and improve the positive impact on the relationship quality of the agricultural supply chain. Retailers should not only pay attention to the significant impact of trust perception on relationship quality but also the impact of suppliers' fairness perception on relationship quality. When suppliers perceive that they are being treated fairly, it will significantly promote trust between suppliers and retailers, thereby increasing the indirect impact of the relationship quality of the agricultural supply chain. Trust perception could improve the relationship quality of the agricultural supply chain. The comprehensive effect of the supplier's fairness perception and trust perception has a more significant impact on the relationship quality of the agricultural supply chain.

5.2. Research Outlook. This study examines the impact of fairness perception and trust perception on the relationship quality of the agricultural supply chain from the suppliers' perspective. The research conclusions provide a theoretical basis for improving the stability of cooperation among members of the agricultural supply chain and improving the efficiency of the agricultural supply chain. In the future, further consideration should be given to the influence of retailers on improving the relationship quality of the agricultural supply chain. In addition, this study analyzes the influence of trust perception on the relationship quality of the supply chain. In the future, we will consider the influence of variables such as solidarity and vendor dependence on the relationship quality of the supply chain.

\section{Data Availability}

The data used to support the findings of this study are collected from agricultural products suppliers in China. The objects of the questionnaire cover 13 major cities in Jiangsu Province, including Changzhou, Zhenjiang, and Wuxi. The data used to support the findings of this study are included within the article. These data are open for the reader after the paper is published in the future. The author can be contacted at syl_nj@njtech.edu.cn.

\section{Conflicts of Interest}

The authors declare that they have no conflicts of interest.

\section{Acknowledgments}

The authors acknowledge the financial support received from the National Natural Science Foundation of China (71301073, 71571099, and 71701092), the Ministry of Education Humanities and Social Sciences Youth Fund (20YJC630142), the Social Science Innovation Team Foundation of Nanjing Tech University (SKTD2017001), and Jiangsu Social Science (Youth) Fund (17GLC009).

\section{References}

[1] W. Keren and J. W. Kristy, "Organisational justice, trust and perceptions of fairness in the implementation of agenda for change," Radiography, vol. 17, no. 1, pp. 61-66, 2011.

[2] U. Broll, P. Welzel, K. Pong Wong et al., "Price risk and risk management in agriculture," Contemporary Economics, vol. 7, no. 2, pp. 17-20, 2013.

[3] Y. S. Du, F. Y. Ma, and J. Y. Zhang, "The impact of perceptions of fairness and efficiency on the stability of supply chain partnerships: environmental uncertainty as a moderating variable," Enterprise Economy, vol. 31, no. 10, pp. 43-47, 2012.

[4] B. X. Li and J. Huang, "On trust and relationship quality," Business Times, vol. 16, no. 12, pp. 25-32, 2005.

[5] H. J. Ma and K. R. Shi, "The trust relationship and contract flexibility of supply chain members: a model of multiple intermediary effects," Journal of Management Engineering, vol. 30, no. 3, pp. 161-169, 2016.

[6] C. Yilmaz, "Relative effects of trust and service quality assessments on perceptions of relationship quality in Interfere relations in the context of conventional distribution channels," Economic and Social Development (ESD), vol. 21, no. 3, pp. 546-553, 2017.

[7] Q. Cheng and L. H. Tian, "Research on supplier trust in supply chain," Logistics Technology, vol. 31, no. 23, pp. 389-392, 2012.

[8] R. Y. Chen, L. Shi, and J. Liu, "Research on safety quality management and incentive mechanism of food supply chain-based on structure, information and relationship quality," Journal of Southeast University (Philosophy and Social Sciences Edition), vol. 15, no. 4, pp. 34-40, 2013.

[9] S. A. Samaha, R. W. Palmatier, and R. P. Dant, "Poisoning relationships: perceived unfairness in channels of distribution," Journal of Marketing, vol. 75, no. 3, pp. 99-117, 2011.

[10] Y. Sun, Z. Liu, and H. Yang, "How does suppliers' fairness affect the relationship quality of agricultural product supply chains?" Journal of Food Quality, vol. 2018, Article ID 9313068, 15 pages, 2018.

[11] G. Elisa, V. Fabio, D. G. Teresa et al., "A theory of planned behaviour perspective for investigating the role of trust in consumer purchasing decision related to short food supply chains," European Journal of Operational Research, vol. 252, no. 1, pp. 170-182, 2016.

[12] J. W. Thibaut and L. Walker, Procedural Justice: A Psychological Analysis, Erlabum Publisher, Hillsdale, MI, USA, 1975.

[13] G. L. Frazier, "Interorganizational exchange behavior in marketing channels: a broadened perspective," Journal of Marketing, vol. 47, no. 4, pp. 68-78, 1983.

[14] H. B. Anneke and S. Achim, "How to treat farmers fairly?results of a farmer survey," The International Food and Agribusiness Management Review, vol. 15, no. 3, pp. 87-97, 2012.

[15] A. Ali, J. K. Pool, and M. R. Jalilvand, "The effect of perceived price fairness through satisfaction and loyalty on international tourists' price acceptance of Islamic-Iranian art products," Education, Business and Society:Contemporary Middle Eastern Issues, vol. 7, no. 4, pp. 201-215, 2014.

[16] S. M. Anna and S. Choi, "The impact of hotel pricing policies on perceived fairness and satisfaction with the reservation process," Journal of Hospitality and Leisure Marketing, vol. 13, no. 1, pp. 25-39, 2006.

[17] L. Myongran, H. G. Lee, S. Jo, and J. Park, "Utility value and fairness consideration for information sharing in a supply chain," Advances in Production Management Systems, vol. 246, pp. 213-220, 2007. 
[18] F. Ye and X. J. Xu, "The impact of trust and relationship commitment between supply chain partnerships on information sharing and operational performance," System Engineering Theory and Practice, vol. 29, no. 8, pp. 36-49, 2009.

[19] M. Khan, M. Hussain, and H. M. Saber, "Information sharing in a sustainable supply chain," International Journal of Production Economics, vol. 181, no. 21, pp. 208-214, 2016.

[20] F. Fossati, S. Hoteit, S. Moretti, and S. Secci, "Fair resource allocation in systems with complete information sharing," IEEE/ACM Transactions on Networking, vol. 26, no. 6, pp. 2801-2814, 2018.

[21] T. Tavor, L. D. Gonen, M. Weber, and U. Spiegel, "The effects of income levels and income inequalities on happiness," Journal of Happiness Studies, vol. 19, no. 7, pp. 2115-2137, 2018.

[22] Z. Yuan, H. Zheng, and Y. Han, "Income level, distribution justice and happiness," Contemporary Finance \& Economics, vol. 35, no. 11, pp. 5-15, 2013.

[23] B. Q. Ouyang and G. S. Zhang, "Intergenerational differences in income level and relative deprivation of migrant workers-an examination and explanation based on the perspective of social justice," Commercial Research, vol. 18, no. 3, pp. 162-170, 2018.

[24] Y. S. Du, F. Y. Ma, and J. Y. Zhang, "The impact of fairness perception and efficiency perception on the stability of supply chain partnerships: the impact of environmental certainty," Business Economy, vol. 34, no. 10, pp. 43-47, 2012.

[25] T. R. Tyler, K. A. Rasinski, and K. M. McGraw, "The influence of perceived injustice on the endorsement of political leaders1," Journal of Applied Social Psychology, vol. 15, no. 8, pp. 700-725, 1985.

[26] K. Kaltenthaler, S. Ceccoli, and R. Gelleny, "Attitudes toward eliminating income inequality in europe," European Union Politics, vol. 9, no. 2, pp. 217-241, 2008.

[27] C. J. Christopher and M. M. Matthew, "The sensitive left and the impervious right: multilevel models and the politics of inequality, ideology, and legitimacy in Europe," Comparative Political Studies, vol. 41, no. 4, pp. 564-599, 2008.

[28] Z. Sonja and C. C. Juan, "Income inequality, distributive fairness and political trust in Latin America," Social Science Research, vol. 52, pp. 179-192, 2015.

[29] N. M. A. Huijts, E. J. E. Molin, and L. Steg, "Psychological factors influencing sustainable energy technology acceptance: a review-based comprehensive framework," Renewable and Sustainable Energy Reviews, vol. 16, no. 1, pp. 525-531, 2012.

[30] N. M. A. Huijts, C. J. H. Midden, and A. L. Meijnders, "Social acceptance of carbon dioxide storage," Energy Policy, vol. 35, no. 5, pp. 2780-2789, 2007.

[31] J. Firestone, W. Kempton, M. B. Lilley, and K. Samoteskul, "Public acceptance of offshore wind power: does perceived fairness of process matter?" Journal of Environmental Planning and Management, vol. 55, no. 10, pp. 1387-1402, 2012.

[32] E. M. Christoph, "Examining the inter-relationships between procedural fairness, trust in actors, risk expectations, perceived benefits, and attitudes towards power grid expansion projects," Energy Policy, vol. 141, pp. 1-9, 2020.

[33] C. Gross, "Community perspectives of wind energy in Australia: the application of a justice and community fairness framework to increase social acceptance," Energy Policy, vol. 35, no. 5, pp. 2727-2736, 2007.

[34] S. Aryee, P. S. Budhwar, and Z. X. Chen, "Trust as a mediator of the relationship between organizational justice and work outcomes: test of a social exchange model," Journal of Organizational Behavior, vol. 23, no. 3, pp. 267-285, 2002.
[35] Z. Ghasem, N. T. Zhaleh, C. H. Stephan et al., "Do supplier perceptions of buyer fairness lead to supplier sales growth?" Industrial Marketing Management, vol. 53, pp. 160-171, 2016.

[36] M. G. Abdul, "Instrumental and interpersonal determinants of relationship satisfaction and commitment in industrial markets," Journal of Business Research, vol. 68, no. 5, pp. 619-628, 2005.

[37] L. Q. Peng and Q. Li, "An empirical study on the impact of distributors' perception of fairness on relationship commitment: a case study of China's home appliance industry," Journal of Guangdong University of Business Studies, vol. 25, no. 4, pp. 31-37+67, 2010.

[38] S. Tan and L. James, "The impact of performance measures on employee fairness perceptions, job satisfaction and organisational commitment," Journal of Applied Management Accounting Research, vol. 10, no. 2, pp. 57-72, 2012.

[39] M. Ziaullah, F. Yi, Y. Feng, S. N. Akhter, and S. Ahmad, "An investigation of justice in supply chain trust and relationship commitment-an empirical study of Pakistan," Journal of Competitiveness, vol. 7, no. 1, pp. 71-87, 2015.

[40] G. F. Huang and X. M. Jia, "Alumni relations, trust and venture capital transactions," Economic Management, vol. 40, no. 7, pp. 161-177, 2018.

[41] W. Cui, "Research on the relationship between trust, market participation and investment income," The Journal of World Economic, vol. 36, no. 9, pp. 127-138, 2013.

[42] Y. Jiang, Y. Liu, and R. Q. Jiang, "An empirical study of P2P online loan platform users' continuous investment willingness based on risk and trust," Business Economy, vol. 36, no. 2, pp. 156-160, 2017.

[43] S. M. Wagner, L. S. Coley, and E. Lindemann, "Effects of suppliers' reputation on the future of buyer-supplier relationships: the mediating roles of outcome fairness and trust," Journal of Supply Chain Management, vol. 47, no. 2, pp. 2948, 2011.

[44] A. Adel, B. Martine, and D. Michel, "Multi-cloud cooperative intrusion detection system:trust and fairness assurance," Annals of Telecommunications, vol. 74, no. 9, pp. 637-653, 2019.

[45] M. Ozawa, "Trust and European-Russian energy cooperation: the case of oil and gas partnerships and long-term contracts," Cambridge Working Papers in Economics, vol. 21, no. 6, pp. 29-37, 2014.

[46] A. H. Hellberg and A. Spiller, "How to treat farmers fairly? results of a farmer survey?" International Food and Agribusiness Management Review, vol. 15, no. 3, pp. 87-98, 2012.

[47] G. L. Frazier, E. Maltz, K. D. Antia, and A. Rindfleisch, "Distributor sharing of strategic information with suppliers," Journal of Marketing, vol. 73, no. 4, pp. 31-43, 2009.

[48] J. C. Anderson and J. A. Narus, "A model of the distributor's perspective of distributor-manufacturer working relationships," Journal of Marketing, vol. 48, no. 4, pp. 62-74, 1984.

[49] J. B. Heide and G. John, "The role of dependence balancing in safeguarding transaction-specific assets in conventional channels," Journal of Marketing, vol. 52, no. 1, pp. 20-35, 1988.

[50] J. L. Price and W. Charles, Handbook of Organizational measurements, Pittman, Marshfield, MA, USA, 1986.

[51] W. C. Kim and R. A. Mauborgne, "Implementing global strategies: the role of procedural justice," Strategic Management Journal, vol. 12, no. S1, pp. 125-143, 1991.

[52] N. Kumar, L. K. Scheer, and J.-B. E. M. Steenkamp, "The effects of supplier fairness on vulnerable resellers," Journal of Marketing Research, vol. 32, no. 1, pp. 54-65, 1995. 
[53] J. P. Meyer, N. J. Allen, and C. A. Smith, "Commitment to organizations and occupations: extension and test of a threecomponent conceptualization," Journal of Applied Psychology, vol. 78, no. 4, pp. 538-551, 1993.

[54] F. Chan, G. K. Lee, E. J. Lee et al., "Structural equation modeling in rehabilitation counseling research," Rehabilitation Counseling Bulletin, vol. 51, no. 1, pp. 44-57, 2007.

[55] K. A. Bollen, Structural Equations with Latent Variables, Wiley-Interscience Publication, New York, NY, USA, 1989. 